\title{
Learning to learn online: creating an open-access learning development platform
}

\author{
Jodie Calleja \\ Canterbury Christ Church University, UK \\ Silvina Bishopp-Martin \\ Canterbury Christ Church University, UK
}

Keywords: Covid-19; online learning; blended learning; learning design; student engagement; student feedback.

\section{The challenge}

In 2018, learning development (LD) at Canterbury Christ Church University (CCCU) followed a mixed-delivery approach, mainly focusing on individual tutorials and embedded sessions in academic programmes. The generic offer of Blackboard resources was limited to a static repository, a collection of materials including PowerPoints and PDFs which lacked interactivity and opportunities to apply and evaluate learning.

In 2019, the Learning Skills Team (LSTeam), made up of faculty-aligned librarians and learning developers, began considering methods for upgrading their online repository. This was in response to analytics revealing the resource was primarily used to book tutorials, indicating students' limited interaction with self-directed learning materials (Calleja, 2020a). The project coincided with a substantial growth in digital technologies for e-learning and greater needs to harness these innovations to enhance online/blended learning (Phillips, McNaught and Kennedy, 2012, p.9). As lockdowns began in 2020, the need to provide students with quality online learning resources grew, exacerbated by increasing requests from programmes for materials on online learning skills and effective online research.

The challenge involved finding a short-term solution in response to the pandemic, whilst also considering a long-term approach to e-learning. Special consideration was given to identifying: a structured model of content delivery (Panigrahi, Srivastava and Sharma, 
2018); a suitable platform for LD content (Francis et al., 2019); methods to engage and assess learning (Castle and McGuire, 2010). The modules needed to be appropriate to our diverse student groups (CCCU, 2021a), be inclusive of different learning needs and account for accessibility regulations (Central Digital and Data Office, 2018). Furthermore, the new platform, the Learning Skills Hub (LSHub) (CCCU, 2021b), needed to be available in advance of the 2020/21 academic year to support the university's blended learning strategy (CCCU, 2021c).

\section{The response}

The LSTeam proposed WordPress to host the LSHub due to its open-access capabilities, allowing access to resources beyond our institution. The design approach involved identifying themes and 'chunking' content to improve engagement and understanding, in line with a micro-learning pedagogy that delivers content in short manageable segments of learning (Major and Calandrino, 2018, p.2). This approach was applied through Hoffman and Ritchie's (1998) ICARE (Introduction, Content, Assessment, Reflection and Extension) model, offering a consistent structure to page design, with consideration to Universal Design for Learning (CAST, 2021). Using this model as a template for all pages would offer students opportunities to practise, reflect on their learning, and extend that learning via links to further resources.

The LSTeam published 20 online modules by August 2020, grouped according to QAA's (2014) HE qualification levels. LSHub pages have been viewed over 36000 times, over six months (Image 1), making it CCCU's most popular non-course specific learning platform. The analytics identify Level 4 modules as the most visited (Image 2), echoing the notion of the first year at university as a key moment of transition in the student journey (Christie et al., 2016). The extensive use of the modules also demonstrates a positive change in user journey in comparison to the use of resources housed in Blackboard repository; greater numbers of students now access asynchronous modules rather than tutorials, which indicates that independent learning opportunities have improved ease of access and interest in development. The conclusion is further supported through student feedback (Image 3), with most respondents reporting the modules are useful, pitched at the right level, and boost confidence in the target skills. 
Image 1. Google analytics of all user stats for the LSHub, 01/12/2020-31/05/2021.

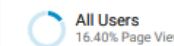

Explorer

- Page Views

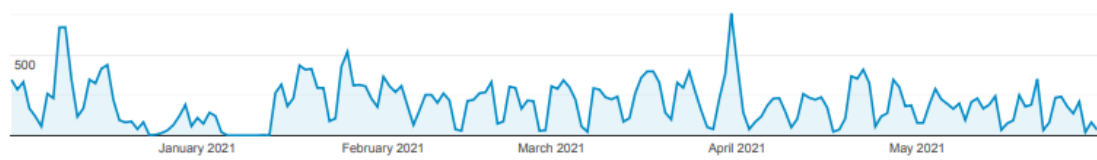

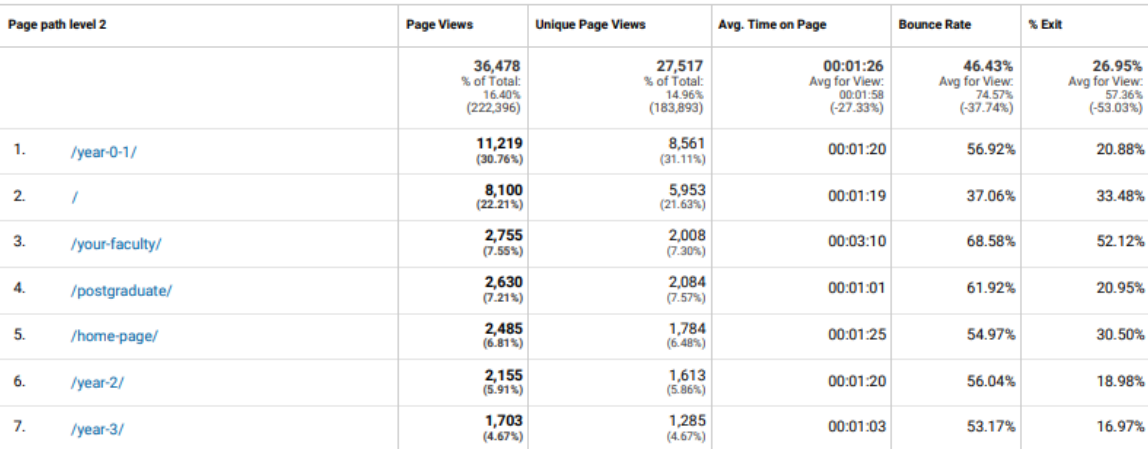

Image 2. Google analytics of all user stats for the LSHub, Level 4 modules, 01/12/2020-31/05/2021.

All Users

Explorer

- Page Views

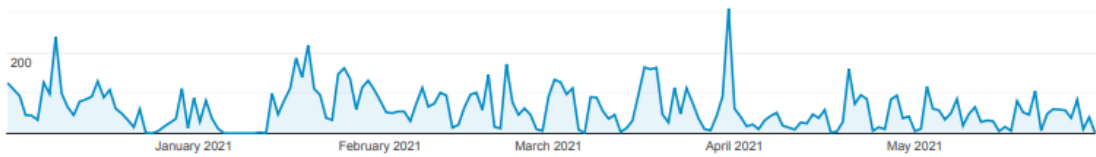

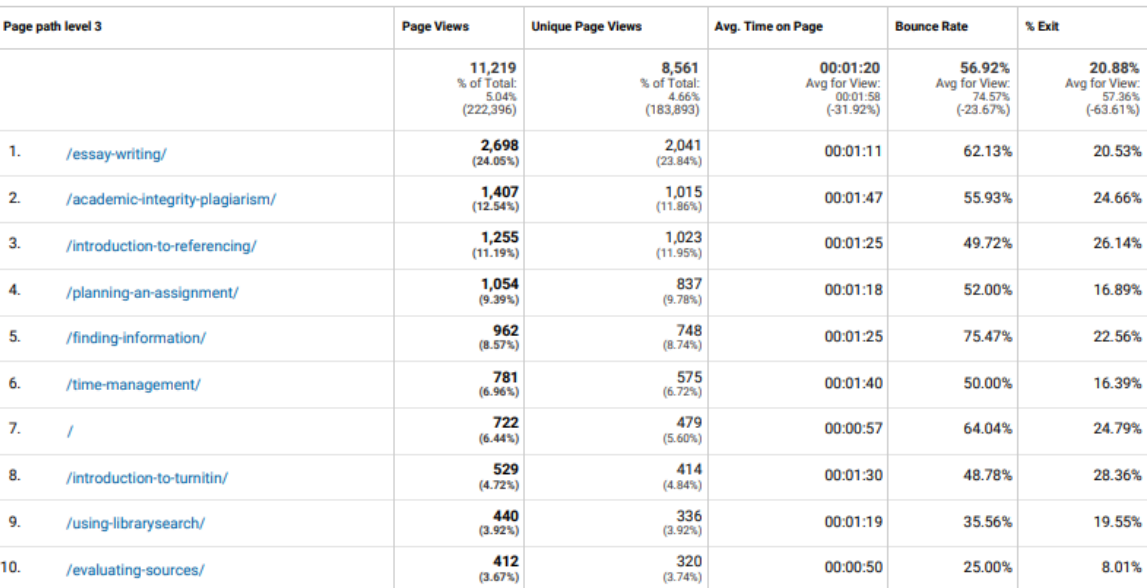




\section{Image 3. Microsoft forms feedback for LSHub modules 17/09/2021-31/05/2021.}

Was the module aimed at the right level for you?

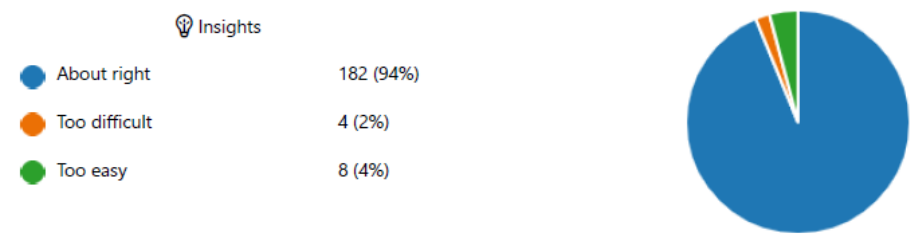

Do you feel more confident after completing this module?

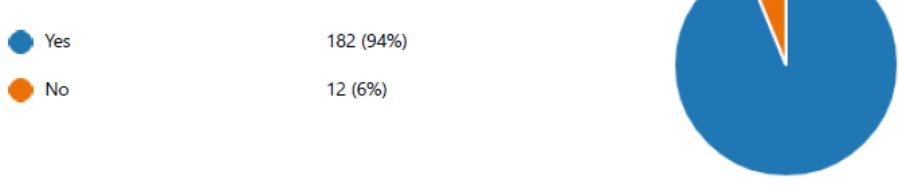

How useful did you find this module?

$\begin{array}{ll}\text { Very useful } & 102(53 \%) \\ \text { Fairly useful } & 83(43 \%) \\ \text { Not at all useful } & 9(5 \%)\end{array}$

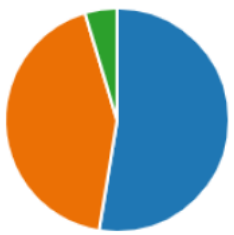

However, there were initially significant challenges promoting the purpose and application of the project to decision-makers, leading to delays in both project approval and access to funding for an appropriate platform. In addition, WordPress presented difficulties meeting accessibility regulations, due to imposed university limitations on licensing, which impacted on the ability to embed diverse and accessible content types. Furthermore, as a new and innovative project, there was no budget to purchase applications, which led to relying on free software with limited accessibility functions and design options. As the project was required to meet a short turnaround (Calleja, 2020b), quality assurance processes were not robust, resulting in some inconsistencies in module length, tone, and style.

\section{Recommendations}

By releasing resources, the LSHub has transformed institutional perspectives of LD, supported by significant user engagement data and positive feedback from staff and students. The LSHub has increased the visibility of the LSTeam and the recognition of academic skills development as an integral part of academic success (Magyar, McAvoy and Forstner, 2011). As a result of this success, the team is now acknowledged in promotional materials for current/prospective students, as well as staff guidance 
documents. Additionally, LSHub modules have been incorporated into assignment briefs, and tutors are beginning to signpost specific modules in assessment feedback, to build opportunities to feed-forward. The prominence and use of the LSHub have led to further collaborations with academic and professional service staff to provide tailored e-learning modules, which will now shape the direction of travel of this project.

Formal quality assurance processes, including student reviews, have recently been implemented, offering the LSTeam and collaborators greater input concerning module development and design. From 2021/2022, the LSHub will become the central platform for all non-course content learning opportunities, to develop a coherent, comprehensive, and high-quality e-learning offer. This will coincide with the platform's imminent move to the university website, a change which will offer greater flexibility in content development, improve quality and ensure accessibility. The recent appointment of a student project assistant will allow the LSTeam to continue to measure success and engagement over the summer 2021. Research will also be conducted in 2021/22 on the impact of LSHub as an embedded learning tool.

On reflection, a similar project is viable with adjustments taken from our lessons learned. We would recommend spending greater time in mapping a similar e-learning platform, using a project management model; developing quality assurance processes from the start; consulting with stakeholders across the university to anticipate long-term development and promote interest in collaborations; gathering wider support for LD curriculum integration using innovative practices.

\section{References}

CAST (2021) The Universal Design for Learning guidelines. Available at: https://udlguidelines.cast.org/binaries/content/assets/udlguidelines/udlg-v22/udlg graphicorganizer v2-2 numbers-yes.pdf (Accessed: 2 June 2021).

Calleja, J. (2020a) Learning Skills Platform Overview. Internal HEI report. Unpublished.

Calleja, J. (2020b) Learning Skills Project Brief. Internal HEI report. Unpublished. 
Canterbury Christ Church University (2021a) Learning and Teaching Strategy 2015-22. Available at: https://www.canterbury.ac.uk/learning-and-teachingenhancement/docs/Learning-and-Teaching-Strategy-2015-2022.pdf (Accessed: 3 June 2021).

Canterbury Christ Church University (2021b) Learning Skills Hub. Available at: https://blogs.canterbury.ac.uk/ccculearningskills/ (Accessed: 7 June 2021).

Canterbury Christ Church University (2021c) Key Blended Learning Principles at Canterbury Christ Church University. Available at: https://cccu.canterbury.ac.uk/Project-2020-21/documents/learning-andteaching/Blended-Learning-Principles-2021.pdf (Accessed: 8 June 2021).

Castle, S. R. and McGuire. C. J. (2010) 'An analysis of student self-assessment of online, blended, and face-to-face learning environments: implications for sustainable education delivery', International Education Studies, 3(3), pp.36-40.

Central Digital and Data Office (2018) Understanding accessibility requirements for public sector bodies. Available at: https://www.gov.uk/guidance/accessibility-requirementsfor-public-sector-websites-and-apps (Accessed: 1 June 2021).

Christie, H., Tett, L., Cree, V. E. and Machine, V. (2016) 'It all just clicked: a longitudinal perspective on transitions within university', Studies in Higher Education, 41(3), pp. 478-490. https://doi.org/10.1080/03075079.2014.942271.

Francis, K., Troop, M., Salter, J., Parahoo, R., Costanzo, L. and Desmarais, S. (2019) 'Scribe hero: an online teaching and learning approach for the development of writing skills in the undergraduate classroom', Online Learning, 23(2), pp.217-234.

Hoffman, B. and Ritchie, D. C. (1998) Teaching and learning online: tools, templates, and training. Available at: https://files.eric.ed.gov/fulltext/ED421092.pdf (Accessed: 4 June 2021).

Magyar, A., McAvoy, D. and Forstner, K. (2011) 'If only we knew what they wanted: bridging the gap between student uncertainty and lecturers' expectations', Journal 
of Learning Development in Higher Education, Issue 3, March, pp.1-18. https://doi.org/10.47408/jldhe.v0i3.68.

Major, A. and Calandrino, T. (2018) 'Beyond chunking: micro-learning secrets for effective online design', Florida Distance Learning Journal, 3(13), pp.1-5. Available at: https://nsuworks.nova.edu/fdla-journal/vol3/iss1/13 (Accessed: 2 June 2021).

Panigrahi, R., Srivastava, P. R. and Sharma, D. (2018) 'Online learning: adoption, continuance \& learning outcome - A review of literature', International Journal of Information Management, 43, pp.1-14.

Phillips, R., McNaught, C. and Kennedy, G. (2012) Evaluating e-learning. Suffolk: Taylor and Francis.

QAA (2014) The Frameworks for Higher Education Qualifications of UK Degree-Awarding Bodies. Available at: https://www.qaa.ac.uk/docs/qaa/quality-code/qualificationsframeworks.pdf (Accessed: 2 June 2021).

\section{Author details}

Jodie Calleja is the Learning Development Manager at Canterbury Christ Church University and holds a PGCE 11-18, MA Education, and FHEA. Her passion is for widening participation through technology and online learning. Jodie holds CeP status and is an active member of the ALDinHE LearnHigher and Peer Mentoring working group. She is also studying for a $\mathrm{PhD}$, applying Foucauldian Discourse Analysis to investigate marginalisation within streams of veganism.

Silvina Bishopp-Martin is the Learning Developer for all Education programmes at Canterbury Christ Church University. She has an MA in TESOL, has achieved CeLP status, is a Fellow of the HEA and a certified CMI Coach and Mentor. Her research interests include peer-mentoring, academic literacies, critical EAP, and LD professionalism and identity. Silvina is a member of the ALDinHE Research \& Development and Peer Mentoring working groups. She is currently undertaking a PhD on Learning Development professional identity and its place in academia. 